\title{
Effect of Concomitant Disease-modifying Antirheumatic Drugs and Methotrexate Administration Route on Biologic Treatment Durability in Rheumatoid Arthritis: OBRI Cohort Results
}

\author{
Arthur N. Lau, J. Carter Thorne, Mohammad Movahedi, Emmanouil Rampakakis, Angela Cesta, \\ Xiuying Li, Sandra Couto, John Sampalis, Claire Bombardier, and the OBRI Investigators
}

\begin{abstract}
Objective. Prior studies have suggested that concurrent conventional synthetic disease-modifying antirheumatic drug (csDMARD) therapy enhances the efficacy of biologic DMARD (bDMARD). Here, we assessed the effect of concomitant csDMARD use and methotrexate (MTX) route of administration on time to bDMARD discontinuation in a large Canadian (Ontario), observational, rheumatoid arthritis (RA) cohort.

Methods. Patients from the Ontario Best Practices Research Initiative (OBRI) who initiated bDMARD therapy and had $\geq 1$ followup assessment were included. The effect of concomitant csDMARD use (primary analysis) and MTX route of administration (secondary analysis) on bDMARD discontinuation owing to (1) any reason, (2) ineffectiveness, (3) adverse events (AE), and (4) both (2) and (3), were assessed with multivariate Cox regression.

Results. Among the 814 patients included, 153 (18.8\%) received bDMARD monotherapy and 661 (81.2\%) combination csDMARD/bDMARD therapy. Over a mean followup of 1.9 years, bDMARD were discontinued in $38.7 \%$ of patients. In multivariate analysis, there was a nonsignificant trend toward lower discontinuation for the csDMARD/bDMARD group compared to bDMARD monotherapy for any reason (HR $0.76,95 \%$ CI $0.55-1.05$ ) and owing to ineffectiveness/AE (HR 0.73 , 95\% CI 0.50-1.06). Further, patients taking combination therapy had significantly lower risk of bDMARD discontinuation due to AE (HR 0.43, 95\% CI 0.24-0.76). In the secondary analysis, no statistical association between MTX dose or route of administration and bDMARD durability was observed.

Conclusion. Concomitant csDMARD use was associated with a significantly lower hazard for bDMARD discontinuation due to AE among patients with RA followed in routine clinical practice in Ontario, Canada. Neither MTX route of administration nor dose were significant predictors of bDMARD durability. (First Release April 15 2019; J Rheumatol 2019;46:874-86; doi:10.3899/ jrheum.180486)
\end{abstract}

Key Indexing Terms:

BIOLOGIC THERAPY

METHOTREXATE

DISEASE-MODIFYING ANTIRHEUMATIC DRUG REGISTRIES LONGITUDINAL STUDIES

From McMaster University, Hamilton, Ontario; Southlake Regional Health Centre, Newmarket, Ontario; Toronto General Hospital Research Institute, University Health Network, Toronto, Ontario; JSS Medical Research; McGill University, Montreal, Quebec; University of Toronto, Department of Medicine and Institute of Health Policy, Management, and Evaluation; Mount Sinai Hospital, Division of Rheumatology, Toronto, Ontario, Canada.

OBRI was funded by peer-reviewed grants from Canadian Institute for Health Research (CIHR), Ontario Ministry of Health and Long-Term Care (MOHLTC), Canadian Arthritis Network (CAN), and unrestricted grants from AbbVie, Amgen, Celgene, Hospira, Janssen, Lilly, Merck, Novartis, Pfizer, Roche, Sanofi, and UCB. MM, AC, XL, SC, and CB are employees at $O B R I$, which was funded by peer-reviewed grants from $C I H R$, MOHLTC, CAN, and unrestricted grants from AbbVie, Amgen, Bristol Myers Squibb, Celgene, Hospital Janssen, Pfizer, Roche, Sanofi, and UCB. ER and JSS are employees at JSS Medical Research, a contract research organization.

A.N. Lau, MD, McMaster University; J.C. Thorne, MD, Southlake Regional Health Centre; M. Movahedi, MD, PhD, Toronto General Hospital Research Institute, University Health Network; E. Rampakakis, PhD, JSS Medical Research; A. Cesta, BSc, Toronto General Hospital

\begin{abstract}
Research Institute, University Health Network; X. Li, BSc, Toronto General Hospital Research Institute, University Health Network; S. Couto, $\mathrm{MSc}$, Toronto General Hospital Research Institute, University Health Network;

J. Sampalis, PhD, JSS Medical Research, and McGill University; C. Bombardier, MD, Toronto General Hospital Research Institute, University Health Network, and University of Toronto, Department of Medicine and Institute of Health Policy, Management, and Evaluation, and Mount Sinai Hospital, Division of Rheumatology.

Address correspondence to Dr. A.N. Lau, 501-25 Charlton Ave. East, Hamilton, Ontario L8N 1Y2, Canada.E-mail: arthur.lau@medportal.ca Accepted for publication October 30, 2018.
\end{abstract}

Rheumatoid arthritis (RA), the most common inflammatory joint disease, is an autoimmune disorder that leads to cartilage and bone damage by specifically targeting the synovial lining of the diarthrodial joints, causing synovitis, disability, and eventually, systemic complications ${ }^{1,2,3,4,5}$. In 
Canada, 272,299 people ( $0.9 \%$ of the Canadian population) were living with RA as of 2010, among whom 233,000 people were experiencing moderate to severe disability owing to RA ${ }^{6}$. The incidence of RA in Canada in 2010 was 17,916 cases and is expected to rise to 23,732 cases by $2040^{6}$.

The goal of RA treatment is remission or low disease activity by reducing inflammation to improve physical function and quality of life, while inhibiting the progression of joint damage $e^{6,7}$. Treatment recommendations in Canada specify that patients with RA should begin conventional synthetic disease-modifying antirheumatic drug (csDMARD) therapy as soon as possible if synovitis is uncontrolled with nonsteroidal antiinflammatory drugs (NSAID), whereas the 2016 guidelines of the European League Against Rheumatism recommend that csDMARD be initiated as soon as RA diagnosis is made $^{8}$. The drug preferred for first-line therapy for moderate to severe disease is methotrexate (MTX), given either orally or parenterally, unless contraindicated ${ }^{7,9}$. Guidelines also recommend that MTX be titrated by rapid-dose escalation up to a maximum of $25 \mathrm{mg}$ per week ${ }^{7,9}$. Combination csDMARD therapy, with MTX as the anchor drug, is recommended for patients with moderate to high RA activity, poor prognosis, or who have inadequate responses to MTX monotherapy ${ }^{7}$. Biologic DMARD (bDMARD) are recommended for patients with no improvement in RA activity after treatment with csDMARD, and are used as a monotherapy or combination therapy ${ }^{7}$.

Previous studies have demonstrated that bDMARD therapy, specifically tumor necrosis factor (TNF) inhibitors, with concomitant csDMARD are more effective at reducing disease activity and preventing structural damage than either component alone ${ }^{10,11,12}$. Further, route of administration has been shown to play a role in the efficacy of MTX in RA, with subcutaneous MTX being more effective than oral MTX, with no differences in tolerability ${ }^{13,14}$.

The purpose of our study was to determine the effect of combination bDMARD and csDMARD treatment, along with the effect of MTX route of administration, on the bDMARD durability, defined as the time to discontinuation, among Ontario patients with RA initiating bDMARD therapy under routine care.

\section{MATERIALS AND METHODS}

Study design. The Ontario Best Practices Research Initiative (OBRI) is a multicenter registry across Ontario, Canada, collecting data from rheumatologists on RA patients followed in routine care. It incorporates rheumatologist assessments and a unique method of collecting data directly from the patients, using telephone interviewers. Patients in the OBRI are interviewed every 6 months, while rheumatologist assessments are conducted as per routine care. All patients have a rheumatologist-confirmed diagnosis of RA, are 18 years or older at enrollment into the registry, have had disease onset after 16 years of age, and have at least 1 swollen joint. Institutional ethics approval was obtained [University Health Network Research Ethics Board (REB) no. 07-0729-AE; full list of REB approvals is included in Supplementary Data 1 , available with the online version of this article], and informed consent was provided by all patients prior to study enrollment. This study was conducted in compliance with the principles of the Declaration of Helsinki.
Study population. For this study, we selected patients with RA enrolled in OBRI between January 2008 and January 2016 who initiated bDMARD (first or subsequent) therapy within 30 days prior to or any time after enrollment in the registry and had at least 1 followup assessment. Patients were followed from the date of bDMARD initiation until bDMARD discontinuation or their last available visit while still receiving bDMARD therapy. Temporary stops of $\leq 180$ days, after which the patients restarted the same bDMARD, were counted as continuous use. Among the 3020 patients enrolled in OBRI, $814(27.0 \%)$ initiated treatment with a biologic with at least 1 followup assessment and these were included in the primary analysis population (Figure 1).

Clinical and patient-reported data. The clinical data collected during physician visits included anticitrullinated protein antibodies and rheumatoid factor (RF) status, patient's global assessment, physician's global assessment, 28-joint tender count, 28-joint swollen count, presence of erosion, RA medication use including, but not limited to, csDMARD and bDMARD, and MTX dose and route of administration. Patient-reported data collected by interviewers included sociodemographic characteristics, Health Assessment Questionnaire-Disability Index (HAQ-DI), and comorbidity profile. Early RA was defined if disease duration was 1 year or less since diagnosis.

Statistical analysis. All analyses were conducted in the primary analysis population. In addition, a secondary analysis was performed among patients who were receiving concomitant MTX (alone or in combination with other csDMARD) at initiation of their bDMARD therapy.

Descriptive statistics, specifically mean and SD for continuous variables and counts and proportions for categorical variables, were produced for all baseline characteristics. Comparisons between patients receiving bDMARD monotherapy versus combination therapy, or between patients taking combination therapy with subcutaneous versus oral MTX, were conducted using the independent samples $t$ test for continuous variables and the chi-square or the Fisher's exact test, as appropriate, for categorical variables. Time to bDMARD discontinuation owing to (1) any reason, (2) ineffectiveness and adverse events (AE), (3) ineffectiveness alone, and (4) AE alone, were assessed using Kaplan-Meier survival analysis, and univariate and multivariate Cox regression.

To examine the independent association of bDMARD monotherapy versus combination therapy or of combination therapy with subcutaneous versus oral MTX, a 2-step approach was followed in which potential confounders were first identified based on whether they reached significance in the univariate survival analysis; these potential confounders, along with age and sex, were then adjusted for in multivariate Cox regression analysis. In addition, a sensitivity analysis was performed for the multivariate analysis by generating 3 additional models considering disease activity measures over time as covariates, given that they may be intervening variables. All statistical analyses were conducted using SAS 9.4 (SAS Institute).

\section{RESULTS}

Overall study population demographics. A total of 814 patients with RA were included in the primary analysis population, among whom $153(18.8 \%)$ were being treated with bDMARD monotherapy at enrollment and the remaining 661 (81.2\%) with combination DMARD therapy, defined as a bDMARD in combination with at least 1 csDMARD (Figure 1). The average age (SD) of the total cohort was 55.7 (12.6) years, with the majority of patients being female $(\mathrm{n}=645 ; 79.2 \%)$, white $(\mathrm{n}=658 ; 80.8 \%)$, and married $(\mathrm{n}=571 ; 70.1 \%)$. One hundred twenty-nine patients were current smokers (15.8\%) and $178 \mathrm{did}$ not have private insurance $(21.9 \%)$.

Demographics based on combination therapy versus

Personal non-commercial use only. The Journal of Rheumatology Copyright (C) 2019. All rights reserved. 
Total number of patients enrolled in registry

$(\mathrm{N}=3,020)$

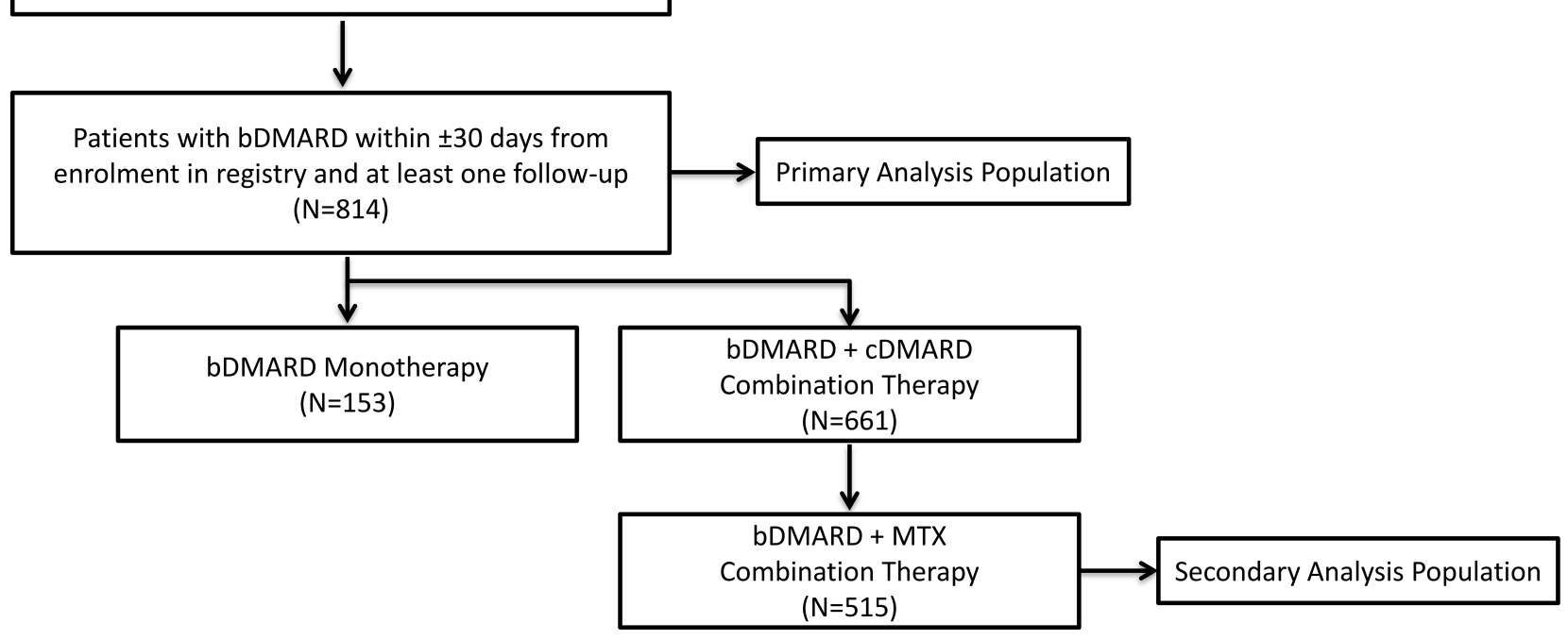

Figure 1. Study flowchart. bDMARD: biologic disease-modifying antirheumatic drug; cDMARD: conventional DMARD; MTX: methotrexate.

bDMARD monotherapy. Key differences in patient sociodemographics based on type of therapy (monotherapy vs combination therapy) are summarized in Table 1. Patients treated with bDMARD monotherapy were older [mean (SD): 57.5 (12.6) vs 55.2 (12.6) yrs; $\mathrm{p}=0.05$ ] and more likely to be in the lower income class $(48.4 \%$ vs $37.2 \%$; $=0.0002)$. No other significant differences were observed between groups.

Demographics based on oral versus subcutaneous MTX and bDMARD combination therapy. Key differences in patient sociodemographics based on route of MTX administration (oral vs subcutaneous) among patients treated with bDMARD combination therapy are summarized in Table 1. Patients treated with oral MTX were less likely to be white $(74.0 \%$ vs $83.5 \% ; \mathrm{p}=0.01)$, less likely to have a post-secondary education $(52.6 \%$ vs $61.3 \%$; $\mathrm{p}=0.03)$, and less likely to be in the higher income class ( $45.6 \%$ vs $54.8 \%$; $\mathrm{p}=0.02$ ) compared to subcutaneous MTX users.

Baseline disease characteristics and medication use in the overall study population. At baseline, the mean (SD) duration of RA in the total cohort was 9.4 (10.0) years, with the majority of patients being RF-positive $(\mathrm{n}=562 ; 69.0 \%)$, biologic-naive $(\mathrm{n}=546 ; 67.1 \%)$, and initiating a TNFi agent ( $\mathrm{n}=676 ; 83.0 \%$; Table 2). Mean (SD) DAS28-ESR was 4.7 (1.4) and HAQ-DI was $1.4(0.8)$. Among patients in the combination therapy group treated with MTX $(n=515), 258$ $(50.1 \%)$ were being treated with at least 1 csDMARD other than MTX, the most common being hydroxychloroquine ( $\mathrm{n}=163 ; 31.7 \%$ ).

Baseline disease characteristics and bDMARD monotherapy versus combination therapy. Patients treated with bDMARD combination therapy were more likely to have early RA
( $20.3 \%$ vs $10.5 \%$; $=0.004)$ and more likely to be treated with a TNFi agent $(84.6 \%$ vs $76.5 \% ; \mathrm{p}=0.02)$, compared to those treated with bDMARD monotherapy (Table 2). Further, at baseline, patients taking combination therapy had significantly lower disease activity, as indicated by the lower mean swollen joint count (7.0 vs 8.2; $\mathrm{p}=0.02)$ and HAQ-DI (1.3 vs $1.5 ; \mathrm{p}=0.05)$, and had fewer comorbidities (2.7 vs 3.3; $\mathrm{p}=0.001)$.

Baseline disease characteristics and bDMARD combination therapy with oral versus subcutaneous MTX. Table 2 summarizes the baseline disease characteristics and medication use based on route of MTX administration. No significant differences were observed in the profile of patients treated with combination bDMARD therapy with oral versus subcutaneous MTX. However, MTX dose was significantly different between groups $(\mathrm{p}<0.0001)$, with patients receiving oral MTX treatment being more likely to receive $15-20 \mathrm{mg}$ per week $(n=148 ; 51.9 \%)$ and those treated with subcutaneous MTX receiving mostly $>20 \mathrm{mg}$ per week $(\mathrm{n}=112 ; 48.7 \%)$.

Primary analysis: time to bDMARD discontinuation by therapy type - Kaplan-Meier analysis. Over a mean (SD) followup of 1.9 (1.6) years, $38.7 \%$ of patients discontinued their bDMARD, including $20.3 \%$ for ineffectiveness, $8.1 \%$ for $\mathrm{AE}$, and $10.3 \%$ for other reasons. The mean overall drug survival was 4.0 years (data not shown).

Figure 2 depicts the time to bDMARD discontinuation by therapy type. Durability of bDMARD treatment was significantly better among patients receiving combination therapy when evaluating discontinuation because of any reason ( $p=0.0473$; Figure 2A), ineffectiveness and AE (combined; $\mathrm{p}=0.0132$; Figure 2B), and AE ( $<0.0001$; Figure 2D).

Personal non-commercial use only. The Journal of Rheumatology Copyright @ 2019 . All rights reserved. 
Table 1. Sociodemographics by type of therapy and by route of MTX administration.

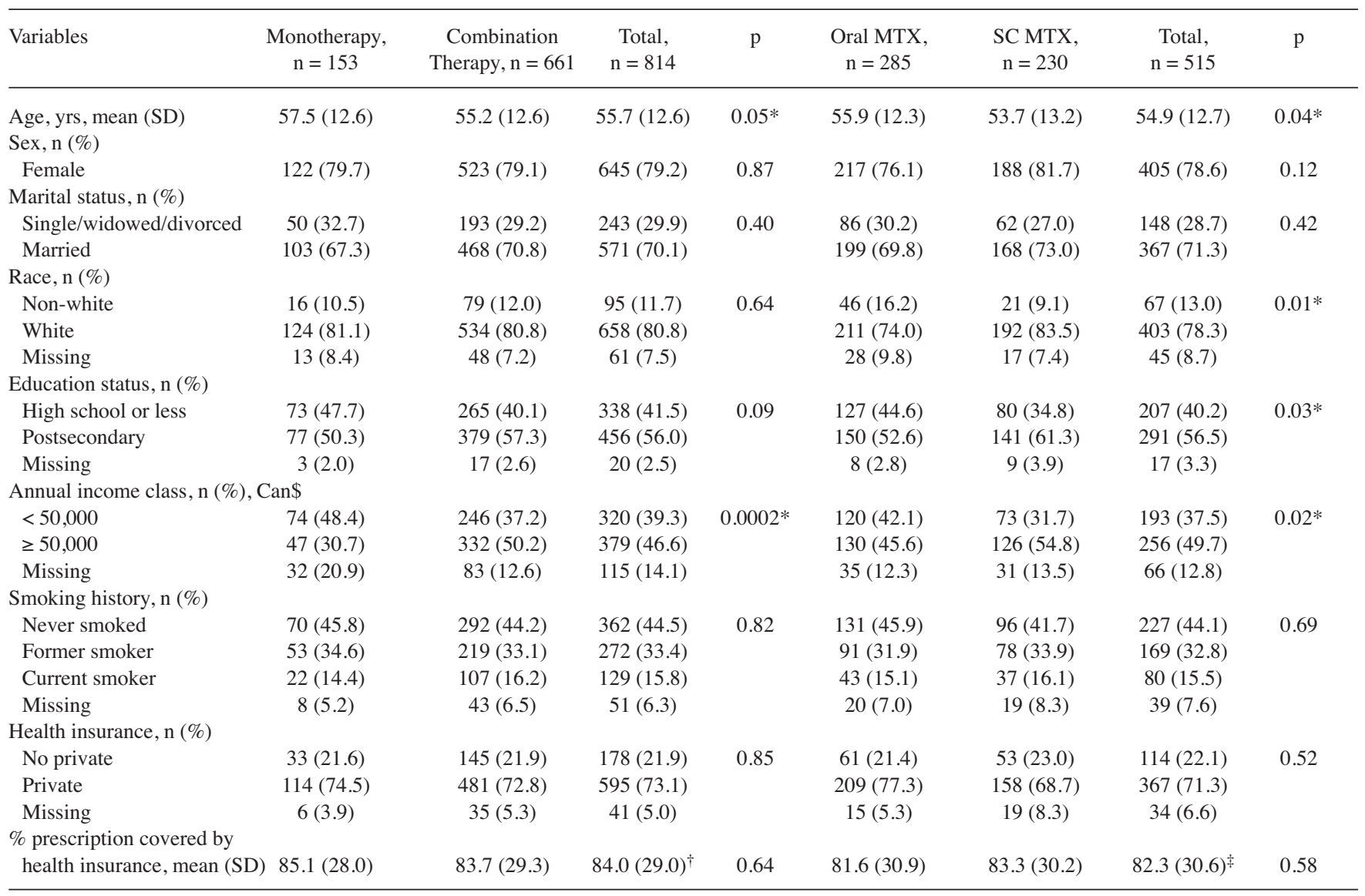

$* \mathrm{p} \leq 0.05 .{ }^{\dagger}$ Available $\mathrm{n}=688 .{ }^{\ddagger}$ Available $\mathrm{n}=436$. MTX: methotrexate; SC: subcutaneous.

However, no significant differences were observed in terms of discontinuation owing to ineffectiveness ( $p=0.8194$; Figure 2C).

Additional predictors of time to bDMARD discontinuation univariate Cox regression. Supplementary Table 1 (available with the online version of this article) summarizes the results of univariate analysis, evaluating the association between bDMARD durability and other factors by reason for bDMARD discontinuation. Generally, the availability of private insurance, higher disease activity over time, and use of concomitant steroids were associated with a significantly higher hazard for bDMARD discontinuation irrespective of reason for discontinuation. Higher number of comorbidities was also associated with increased hazard for bDMARD discontinuation, reaching statistical significance only for discontinuation for any reason, while use of NSAID was a negative predictor of bDMARD discontinuation for safety reasons.

Time to BDMARD discontinuation - multivariate Cox regression. Upon adjusting for the potential confounders that were identified in the univariate survival analyses (Supplementary Table 1, available with the online version of this article), combination bDMARD therapy remained a significant predictor of improved bDMARD durability (i.e., longer time to discontinuation) because of AE (adjusted HR $0.43,95 \%$ CI 0.24-0.76; $p=0.004$; Table 3). However, no significant association was observed with discontinuation due to other reasons.

A sensitivity analysis of the effect of therapy type on bDMARD discontinuation was also performed, considering disease activity measures over time (Supplementary Tables 2 and 3 , available with the online version of this article). The results of these analyses were comparable to the main analysis.

Secondary analysis: time to bDMARD discontinuation by MTX administration route - Kaplan-Meier analysis. Figure 3 depicts the time to bDMARD discontinuation by route of administration of concomitant MTX therapy. No significant association was observed between route of MTX administration and durability of bDMARD treatment, irrespective of the reason for bDMARD discontinuation.

Time to bDMARD discontinuation - univariate Cox regression. Supplementary Table 4 (available with the online version of this article) summarizes the results of univariate

Personal non-commercial use only. The Journal of Rheumatology Copyright @) 2019. All rights reserved. 
Table 2. Baseline disease characteristics and medication use by therapy type and by route of MTX administration.

\begin{tabular}{|c|c|c|c|c|c|c|c|c|}
\hline Characteristics & $\begin{array}{l}\text { Monotherapy, } \\
n=153\end{array}$ & $\begin{array}{l}\text { Combination } \\
\text { Therapy, } \mathrm{n}=661\end{array}$ & $\begin{array}{c}\text { Total, } \\
\mathrm{n}=814\end{array}$ & $\mathrm{p}$ & $\begin{array}{l}\text { Oral MTX, } \\
\mathrm{n}=285\end{array}$ & $\begin{array}{c}\text { SC MTX, } \\
n=230\end{array}$ & $\begin{array}{c}\text { Total, } \\
\mathrm{n}=515\end{array}$ & $\mathrm{p}$ \\
\hline \multicolumn{9}{|l|}{ Disease characteristics } \\
\hline Early $\mathrm{RA}^{\ddagger}, \mathrm{n}(\%)$ & $16(10.5)$ & $134(20.3)$ & $150(18.4)$ & $0.004^{*}$ & $63(22.1)$ & $50(21.7)$ & $113(21.9)$ & 0.92 \\
\hline \multicolumn{9}{|l|}{ Ever presence of erosion, $\mathrm{n}(\%)$} \\
\hline Yes & $79(51.6)$ & $314(47.5)$ & $393(48.3)$ & $0.002 *$ & $128(44.9)$ & $115(50.0)$ & $243(47.2)$ & 0.17 \\
\hline \multicolumn{9}{|l|}{ RF-positive, n (\%) } \\
\hline Yes & $106(69.3)$ & $456(69.0)$ & $562(69.0)$ & 0.20 & $202(70.9)$ & $159(69.1)$ & $361(70.1)$ & 0.17 \\
\hline Missing & $19(12.4)$ & $43(6.5)$ & $62(7.7)$ & & $24(8.4)$ & $9(3.9)$ & $33(6.4)$ & \\
\hline Swollen joint count $(0-28)$, mean $(S D)^{\S}$ & $8.2(5.8)$ & $7.0(5.0)$ & $7.2(5.2)$ & $0.02 *$ & $6.8(5.1)$ & $6.6(4.4)$ & $6.7(4.8)$ & 0.61 \\
\hline Tender joint count $(0-28)$, mean $(S D)^{9}$ & $7.5(6.3)$ & $7.6(7.0)$ & $7.6(6.6)$ & 0.90 & $7.8(6.7)$ & $6.9(5.8)$ & $7.4(6.3)$ & 0.12 \\
\hline DAS28-ESR, mean (SD) & $4.8(1.4)$ & $4.7(1.4)$ & $4.7(1.4)$ & 0.64 & $4.7(1.4)$ & $4.6(1.4)$ & $4.7(1.4)$ & 0.45 \\
\hline \multicolumn{9}{|l|}{ Medication use } \\
\hline Prior use of csDMARD, n (\%) & $147(96.1)$ & $601(90.9)$ & 748 (91.9) & 0.43 & $264(92.6)$ & $204(88.7)$ & $468(90.9)$ & 0.12 \\
\hline Prior use of bDMARD, n (\%) & $75(49.0)$ & $193(29.2)$ & $268(32.9)$ & $<0.0001^{*}$ & $87(30.5)$ & $57(24.8)$ & $144(27.9)$ & 0.14 \\
\hline \multicolumn{9}{|l|}{ Type of bDMARD, n (\%) } \\
\hline Non-TNFi & $36(23.5)$ & $102(15.4)$ & $138(17.0)$ & $0.02 *$ & $37(13.0)$ & $36(15.7)$ & $73(14.2)$ & 0.39 \\
\hline TNFi & $117(76.5)$ & $559(84.6)$ & $676(83.0)$ & & $248(87.0)$ & $194(84.3)$ & $442(85.8)$ & \\
\hline Use of MTX at start of bDMARD, n (\%) & ) NA & $515(78.0)$ & $515(66.3)$ & NA & $285(100)$ & $230(100)$ & $515(100)$ & NA \\
\hline \multicolumn{9}{|c|}{ Additional use of csDMARD in MTX users, $\mathrm{n}(\%)$} \\
\hline At least 1 csDMARD other than MTX & $\mathrm{NA}$ & $258(50.1)^{\ddagger \ddagger \ddagger}$ & $258(50.1)^{\ddagger \ddagger}$ & NA & $144(50.5)$ & $114(49.6)$ & $258(50.1)$ & 0.14 \\
\hline Hydroxychloroquine & NA & $163(31.7)^{\ddagger \ddagger \dagger}$ & $163(31.7)^{\dagger \neq \ddagger}$ & NA & $87(30.5)$ & $76(33.0)$ & $163(31.7)$ & 0.54 \\
\hline Leflunomide & NA & $108(21.0)^{\dagger \ddagger \dagger}$ & $108(21.0)^{\text {辡市 }}$ & NA & $62(21.8)$ & $46(20.0)$ & $108(21.0)$ & 0.63 \\
\hline Sulfasalazine & NA & $72(14.0)^{\ddagger \ddagger \ddagger}$ & $72(14.0)^{\dagger \dagger \ddagger}$ & NA & $34(11.9)$ & $38(16.5)$ & $72(14.0)$ & 0.14 \\
\hline$>20$ & & & & & $56(19.7)$ & $112(48.7)$ & $168(32.6)$ & \\
\hline
\end{tabular}

* Statistically significant $\mathrm{p}$ value. ${ }^{\ddagger}$ Disease duration $\leq 1$ year. ${ }^{\S}$ Available $\mathrm{n}=682$ (435 for MTX users). ${ }^{9}$ Available $\mathrm{n}=671$ (429 for MTX users). ${ }^{\dagger \dagger}$ Available $\mathrm{n}=586$ (374 for MTX users). ${ }^{\ddagger}$ Available $\mathrm{n}=618$ (398 for MTX users). ${ }^{\S}$ Available $\mathrm{n}=615$ (397 for MTX users). IJ Available $\mathrm{n}=583$ (367 for MTX users). t† Available $\mathrm{n}=765$ (483 for MTX users). erythrocyte sedimentation rate; csDMARD: conventional synthetic disease-modifying antirheumatic drugs; bDMARD: biologic DMARD; HAQ-DI: Health Assessment Questionnaire-Disability Index; MTX: methotrexate; NA: not available; PGA: physician's global assessment; PtGA: patient's global assessment; RA: rheumatoid arthritis; RF: rheumatoid factor; SC: subcutaneous; TNFi: tumor necrosis factor inhibitor.

analysis, evaluating the association between bDMARD durability and factors other than route of MTX administration, by reason for bDMARD discontinuation. Higher disease severity over time was associated with a significantly higher hazard for bDMARD discontinuation irrespective of reason for discontinuation. In addition, higher HAQ-DI score at baseline, concomitant use of additional csDMARD at baseline or over time, use of steroids over time, and higher dose of MTX were also identified as positive predictors of bDMARD discontinuation due to ineffectiveness but not safety reasons.
Time to DDMARD discontinuation - multivariate Cox regression in the second analysis. Multivariate survival analyses, adjusting for potential confounders that were identified in the univariate survival analyses for patients treated with bDMARD and MTX (Supplementary Table 4, available with the online version of this article), were performed for each of the 4 bDMARD discontinuation reasons to examine the independent effect of oral MTX versus subcutaneous MTX (Table 3). The route of MTX administration was not significantly associated with the time to bDMARD discontinuation, irrespective of the reason for 


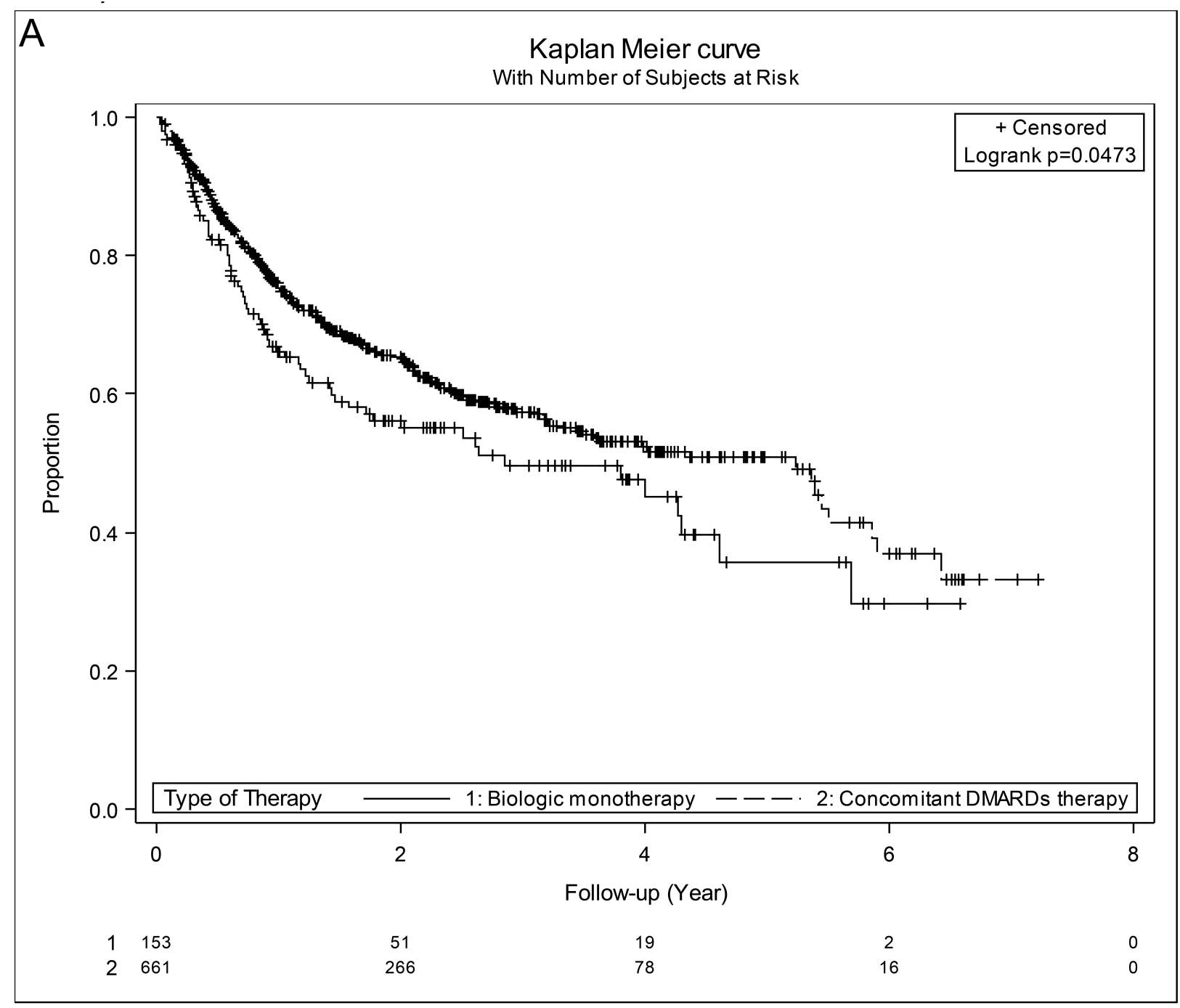

Figure 2. Kaplan-Meier survival curves for time to bDMARD discontinuation due to (A) any reason, (B) ineffectiveness and adverse events, (C) ineffectiveness, (D) adverse events based on type of therapy by discontinuation reason. DMARD: disease-modifying antirheumatic drug; bDMARD: biologic DMARD.

bDMARD discontinuation. Similar results were obtained in sensitivity analyses to those described in the primary analysis (Supplementary Tables 5 and 6, available with the online version of this article).

\section{DISCUSSION}

The objective of our study was to determine whether concomitant use of csDMARD has an effect on the real-world durability of bDMARD treatment among patients with RA. Further, the effect of route of MTX administration on bDMARD durability was also explored.

Upon adjusting for potential confounders, patients who were treated with combination csDMARD/bDMARD therapy were significantly less likely to discontinue their bDMARD because of AE. There was a nonsignificant trend of lower discontinuation for the combination csDMARD/bDMARD therapy compared to bDMARD monotherapy groups for any reason, and because of ineffectiveness and AE. No association was observed between MTX route of administration and bDMARD discontinuation because of ineffectiveness and/or AE, or for any reason.

Results from the British Society for Rheumatology Biologics Register showed that concomitant use of MTX, but not other csDMARD, with bDMARD was associated with improved bDMARD durability ${ }^{15}$. Although we observed an association in the same direction, it was not statistically significant, which may be attributed to the fact that our primary analysis was not limited to MTX but rather all csDMARD, or to the smaller sample size of our study. Interestingly, patients taking biologic monotherapy were

Personal non-commercial use only. The Journal of Rheumatology Copyright (C) 2019. All rights reserved. 


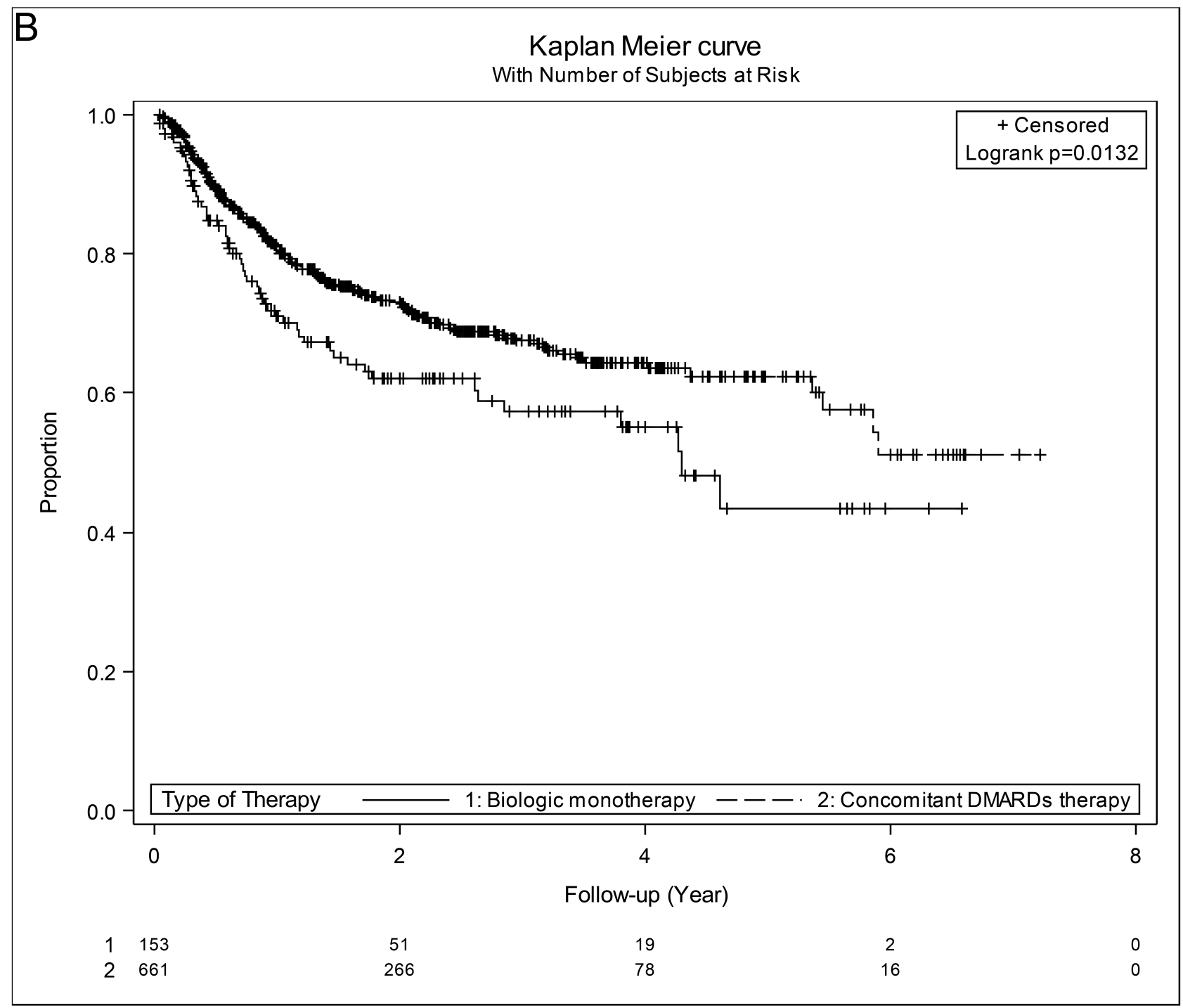

Figure 2. Continued

more likely to discontinue therapy because of AE, which may seem counterintuitive, given the known potential AE associated with csDMARD, particularly MTX. We hypothesize there may be a channeling bias, in which patients in the registry selected for monotherapy treatment were more likely to have failed prior antirheumatic treatment, including biologics, owing to intolerance, and were therefore inherently more likely to fail future therapies because of intolerance. Unfortunately, information regarding the reason for discontinuation of previous treatments prior to registry enrollment was not available. Soliman, et al also made the same observation $^{15}$, which led the authors to suggest a similar bias. Alternatively, despite adjustment for known potential confounders, there is always the risk for residual confounding that may be associated with our observation.

In a previous study investigating the effectiveness of oral versus subcutaneous MTX, Hazlewood, et al showed that, upon adjusting for potential confounders, patients with early RA treated with subcutaneous MTX had substantially lower rates of treatment failure and significantly lower DAS28 levels, indicating higher efficacy ${ }^{14}$. In our study, treatment with subcutaneous versus oral MTX in combination with bDMARD did not have an effect on bDMARD durability; however, this could be due to the masking of the effect of MTX administration by the concomitant use of bDMARD or to the inclusion of patients both with early disease and with established disease. It is worth noting that the practice of using subcutaneous MTX is more recent than the oral route and would explain the higher percentage of patients with early RA.

A potential limitation of our study relates to the relatively small sample size compared to some other similar national 


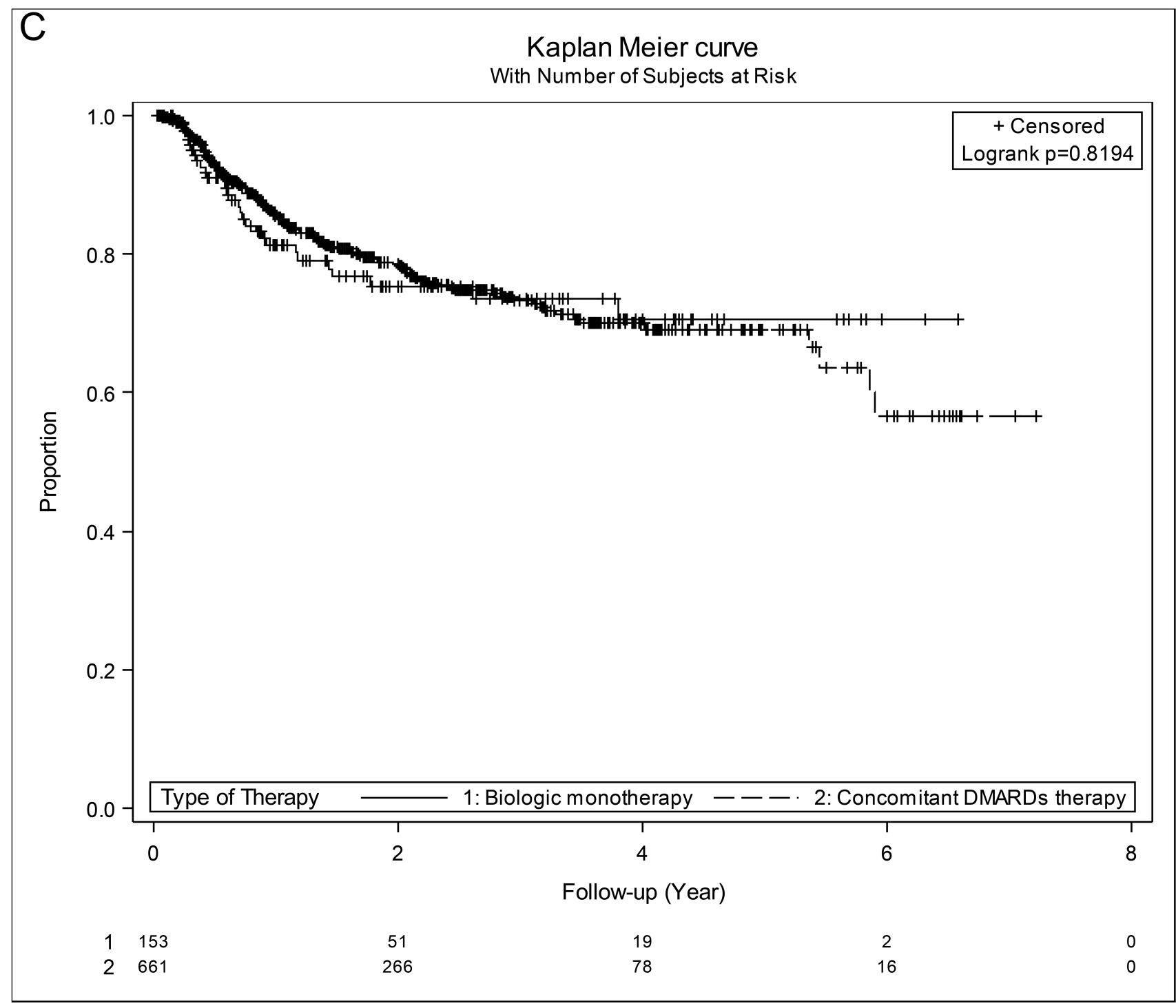

Figure 2. Continued

registries, particularly in certain subgroups of patients (e.g., previously biologic-naive patients taking bDMARD monotherapy), which may have limited our statistical power to identify certain predicting variables as significant. Because of this sample size limitation, we also preferred to exclude only those patients who started their bDMARD more than 30 days before their enrollment into the registry rather than exclude all patients with ever use of bDMARD.

We have demonstrated that concomitant use of csDMARD was associated with a significantly lower hazard for bDMARD discontinuation resulting from safety reasons among patients with RA in Ontario followed in routine clinical practice. In addition, neither route of administration nor dose of MTX were significant predictors of bDMARD durability. Overall, these results support the use of bDMARD in combination with csDMARD among patients with active
RA, and suggest that either oral or subcutaneous MTX is appropriate when used in combination with a bDMARD.

\section{ONLINE SUPPLEMENT}

Supplementary material accompanies the online version of this article.

\section{REFERENCES}

1. Cojocaru M, Cojocaru IM, Silosi I, Vrabie CD, Tanasescu R. Extra-articular manifestations in rheumatoid arthritis. Maedica 2010;5:286-91

2. Firestein GS. Evolving concepts of rheumatoid arthritis. Nature 2003;423:356-61.

3. Goldring SR. Pathogenesis of bone and cartilage destruction in rheumatoid arthritis. Rheumatology 2003;42 Suppl 2:ii11-6.

4. Karmakar S, Kay J, Gravallese EM. Bone damage in rheumatoid arthritis: Mechanistic insights and approaches to prevention. Rheum Dis Clin North Am 2010;36:385-404.

5. Yanni G, Whelan A, Feighery C, Bresnihan B. Synovial tissue

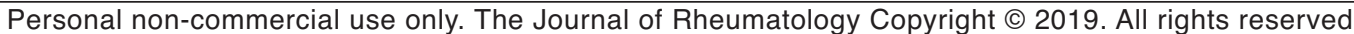




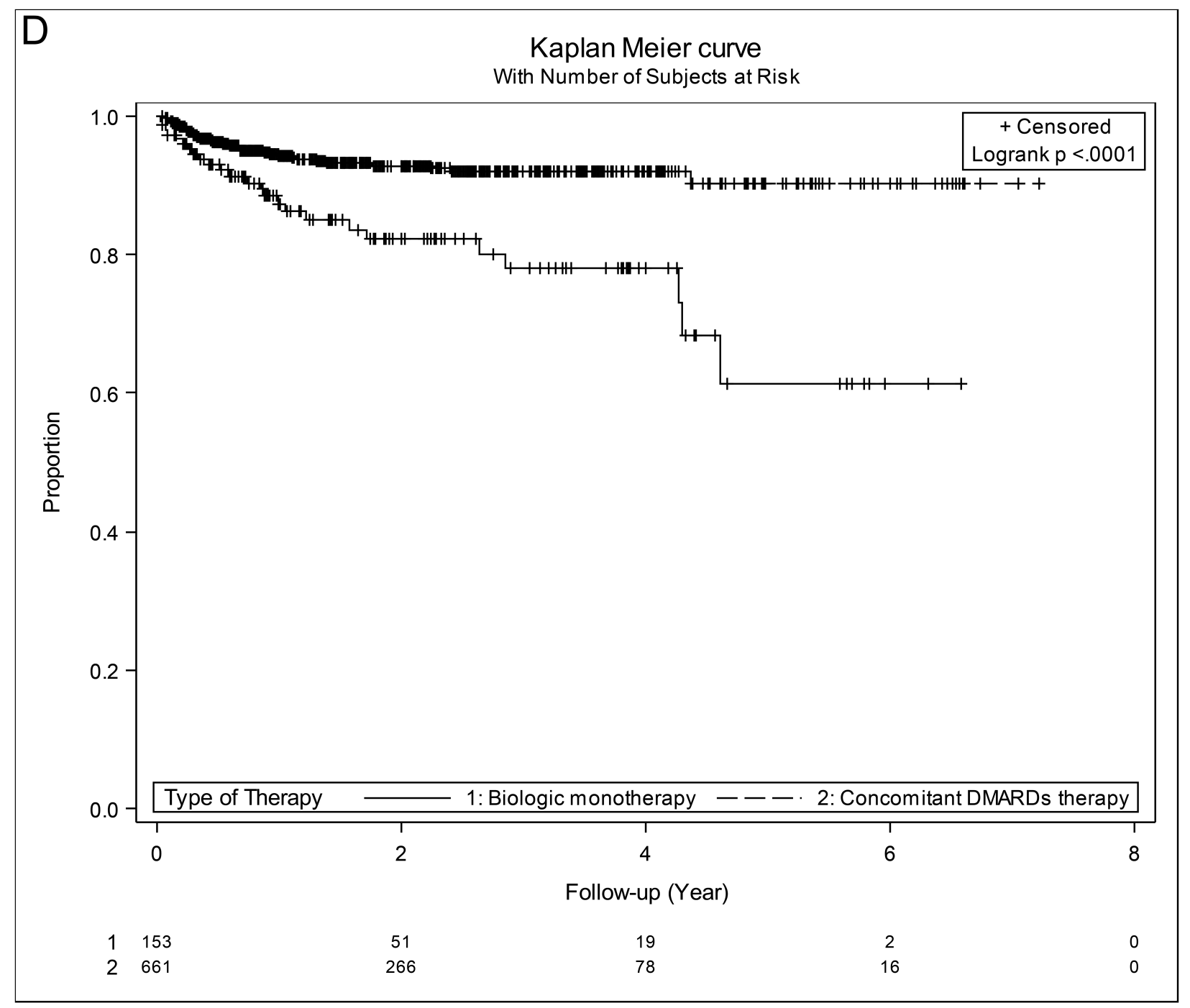

Figure 2. Continued

Table 3. Effect of therapy type and route of MTX administration on bDMARD discontinuation by reason for discontinuation - multivariate Cox regression.

\begin{tabular}{|c|c|c|c|c|}
\hline \multirow[t]{2}{*}{ Reason for Discontinuation } & \multicolumn{2}{|c|}{ Combination vs Monotherapy } & \multicolumn{2}{|c|}{ SC vs Oral MTX } \\
\hline & AHR $(95 \%$ CI $)$ & $\mathrm{p}$ & AHR $(95 \% \mathrm{CI})$ & $\mathrm{p}$ \\
\hline Any reason & $0.76(0.55-1.05)^{\dagger}$ & 0.10 & $0.98(0.78-1.24)^{¥}$ & 0.87 \\
\hline Ineffectiveness & $1.09(0.69-1.74)^{5}$ & 0.70 & $1.17(0.82-1.67)^{€}$ & 0.39 \\
\hline $\mathrm{AE}$ & $0.43(0.24-0.76)^{\S}$ & $0.004 *$ & $0.94(0.56-1.60)^{\circledR}$ & 0.83 \\
\hline
\end{tabular}

* Statistically significant $\mathrm{p}$ value. ${ }^{\dagger}$ Adjusted for age, sex, insurance type, no. comorbidities at baseline, baseline HAQ-DI, prior use of bDMARD, and steroid use over time. ${ }^{\ddagger}$ Adjusted for age, sex, insurance type, baseline HAQ-DI, and steroid use over time. ${ }^{\Phi}$ Adjusted for age, sex, baseline HAQ-DI, and steroid use over time. ${ }^{\S}$ Adjusted for age, sex, insurance type, steroid use over time, and NSAID use over time. ${ }^{\ddagger}$ Adjusted for age, sex, RA duration at baseline, additional csDMARD use at baseline and over time, steroid use over time, and MTX dose over time. ${ }^{£}$ Adjusted for age, sex, baseline HAQ-DI, additional DMARD use at baseline and over time, steroid use over time, and MTX dose over time. ${ }^{€}$ Adjusted for age, sex, baseline HAQ-DI, steroid use over time, additional csDMARD use over time, and MTX dose over time. ${ }^{\circledR}$ Adjusted for age and sex. AHR: adjusted HR; AE: adverse event; bDMARD: biologic disease-modifying antirheumatic drug; csDMARD: conventional synthetic DMARD; HAQ-DI: Health Assessment Questionnaire-Disability Index; MTX: methotrexate; NSAID: nonsteroidal antiinflammatory drug; SC: subcutaneous; RA: rheumatoid arthritis. 


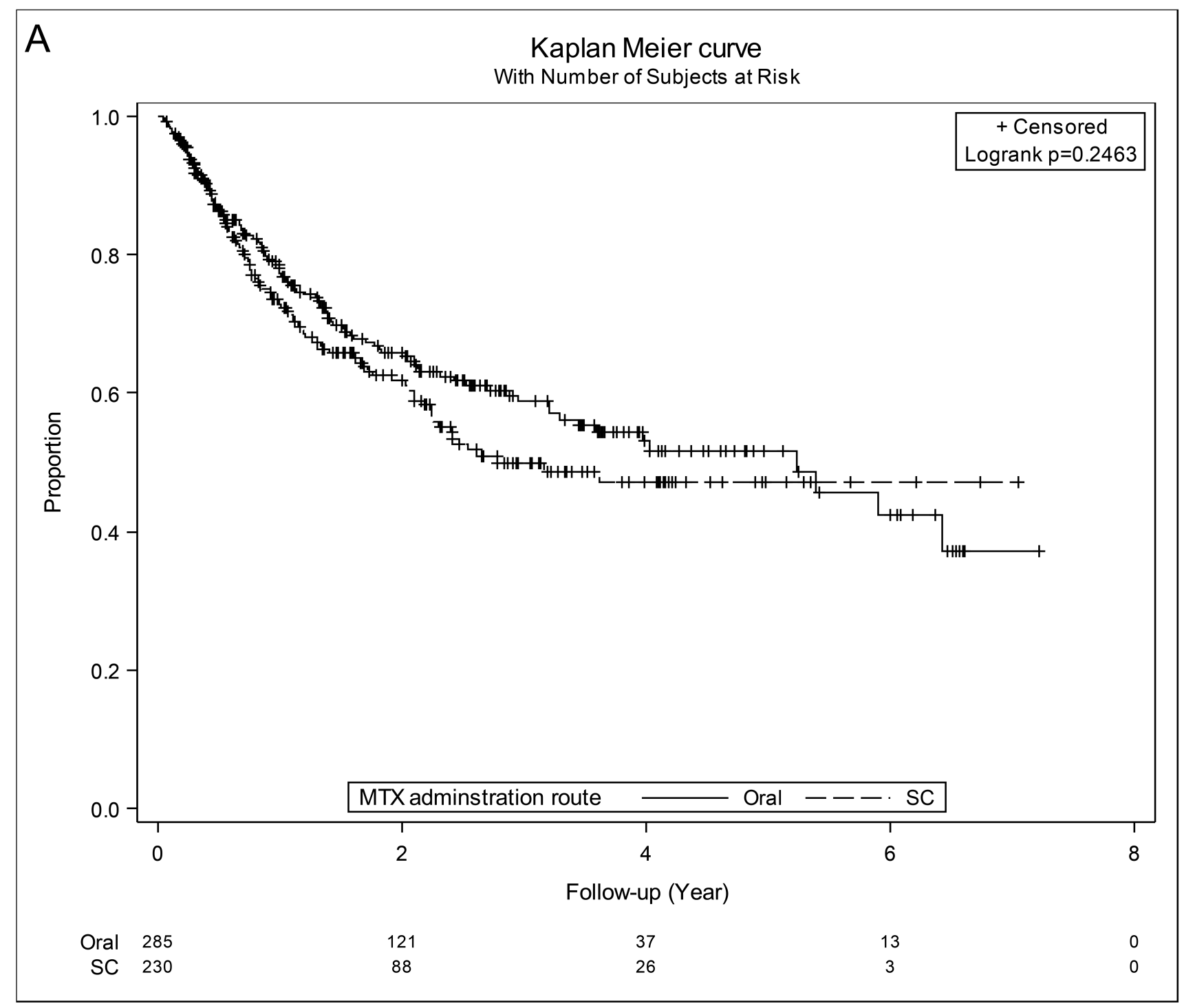

Figure 3. Kaplan-Meier survival curves for time to bDMARD discontinuation due to (A) any reason, (B) ineffectiveness and adverse events, (C) ineffectiveness, (D) adverse events based on route of MTX administration by discontinuation reason. bDMARD: biologic disease-modifying antirheumatic drug; MTX: methotrexate; SC: subcutaneous.

macrophages and joint erosion in rheumatoid arthritis. Ann Rheum Dis 1994;53:39-44.

6. Arthritis Alliance of Canada. The impact of arthritis in Canada: today and over the next 30 years. [Internet. Accessed January 17, 2019.] Available from:

www.arthritisalliance.ca/en/initiativesen/impact-of-arthritis

7. Bykerk VP, Akhavan P, Hazlewood GS, Schieir O, Dooley A, Haraoui B, et al; Canadian Rheumatology Association. Canadian Rheumatology Association recommendations for pharmacological management of rheumatoid arthritis with traditional and biologic disease-modifying antirheumatic drugs. J Rheumatol 2012; 39:1559-82.

8. Smolen JS, Landewe R, Bijlsma J, Burmester G, Chatzidionysiou K, Dougados $\mathrm{M}$, et al. EULAR recommendations for the management of rheumatoid arthritis with synthetic and biological disease-modifying antirheumatic drugs: 2016 update. Ann Rheum Dis 2017;76:960-77.

9. Bornstein C, Craig M, Tin D. Practice guidelines for pharmacists: the pharmacological management of rheumatoid arthritis with traditional and biologic disease-modifying antirheumatic drugs. Can Pharm J 2014;147:97-109.

10. Breedveld FC, Weisman MH, Kavanaugh AF, Cohen SB, Pavelka $\mathrm{K}$, van Vollenhoven R, et al. The PREMIER study: a multicenter, randomized, double-blind clinical trial of combination therapy with adalimumab plus methotrexate versus methotrexate alone or adalimumab alone in patients with early, aggressive rheumatoid arthritis who had not had previous methotrexate treatment. Arthritis Rheum 2006;54:26-37.

11. Hyrich KL, Symmons DP, Watson KD, Silman AJ; British Society for Rheumatology Biologics Register. Comparison of the response 


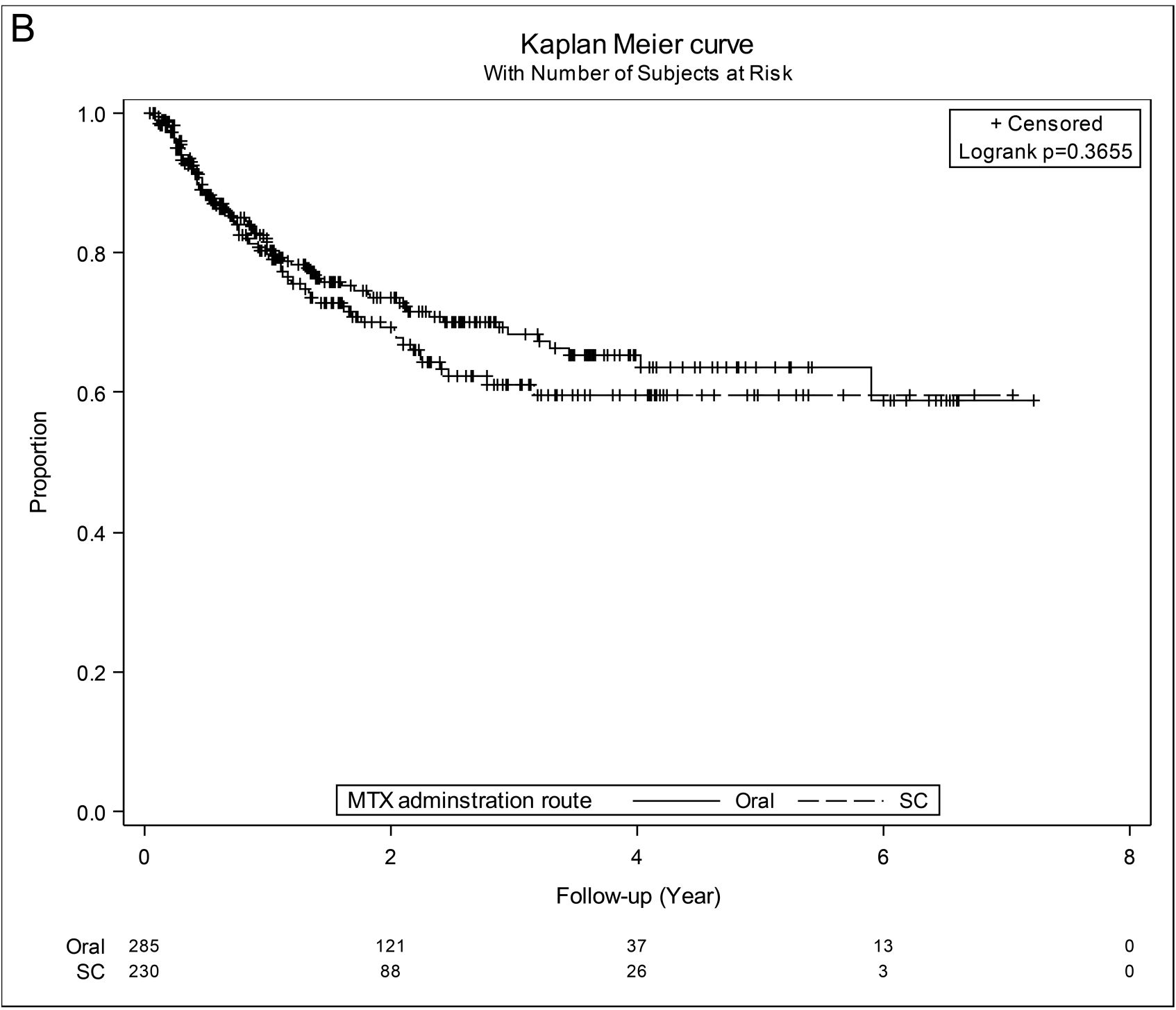

Figure 3. Continued

to infliximab or etanercept monotherapy with the response to cotherapy with methotrexate or another disease-modifying antirheumatic drug in patients with rheumatoid arthritis: Results from the British Society for Rheumatology Biologics Register. Arthritis Rheum 2006;54:1786-94.

12. Klareskog L, van der Heijde D, de Jager JP, Gough A, Kalden J, Malaise M, et al; TEMPO (Trial of Etanercept and Methotrexate with Radiographic Patient Outcomes) study investigators. Therapeutic effect of the combination of etanercept and methotrexate compared with each treatment alone in patients with rheumatoid arthritis: Double-blind randomised controlled trial. Lancet 2004;363:675-81.

13. Braun J, Kastner P, Flaxenberg P, Wahrisch J, Hanke P, Demary W, et al ; MC-MTX.6/RH Study Group. Comparison of the clinical efficacy and safety of subcutaneous versus oral administration of methotrexate in patients with active rheumatoid arthritis: results of a six-month, multicenter, randomized, double-blind, controlled, phase IV trial. Arthritis Rheum 2008;58:73-81.

14. Hazlewood GS, Thorne JC, Pope JE, Lin D, Tin D, Boire G, et al; $\mathrm{CATCH}$ Investigators. The comparative effectiveness of oral versus subcutaneous methotrexate for the treatment of early rheumatoid arthritis. Ann Rheum Dis 2016;75:1003-8.

15. Soliman MM, Ashcroft DM, Watson KD, Lunt M, Symmons DP, Hyrich KL, et al; British Society for Rheumatology Biologics Register. Impact of concomitant use of DMARDs on the persistence with anti-TNF therapies in patients with rheumatoid arthritis: results from the British Society for Rheumatology Biologics Register. Ann Rheum Dis 2011;70:583-9. 


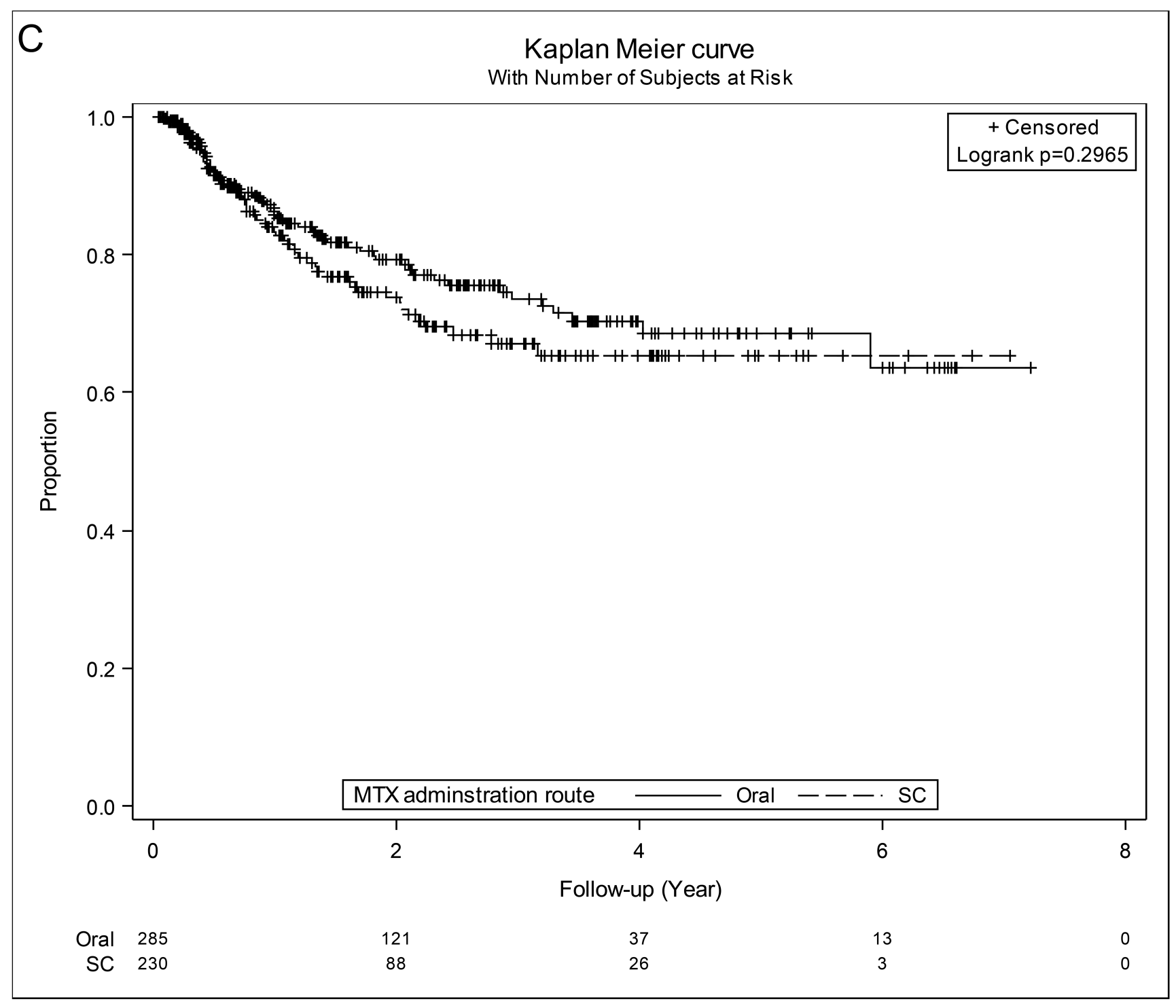

Figure 3. Continued 


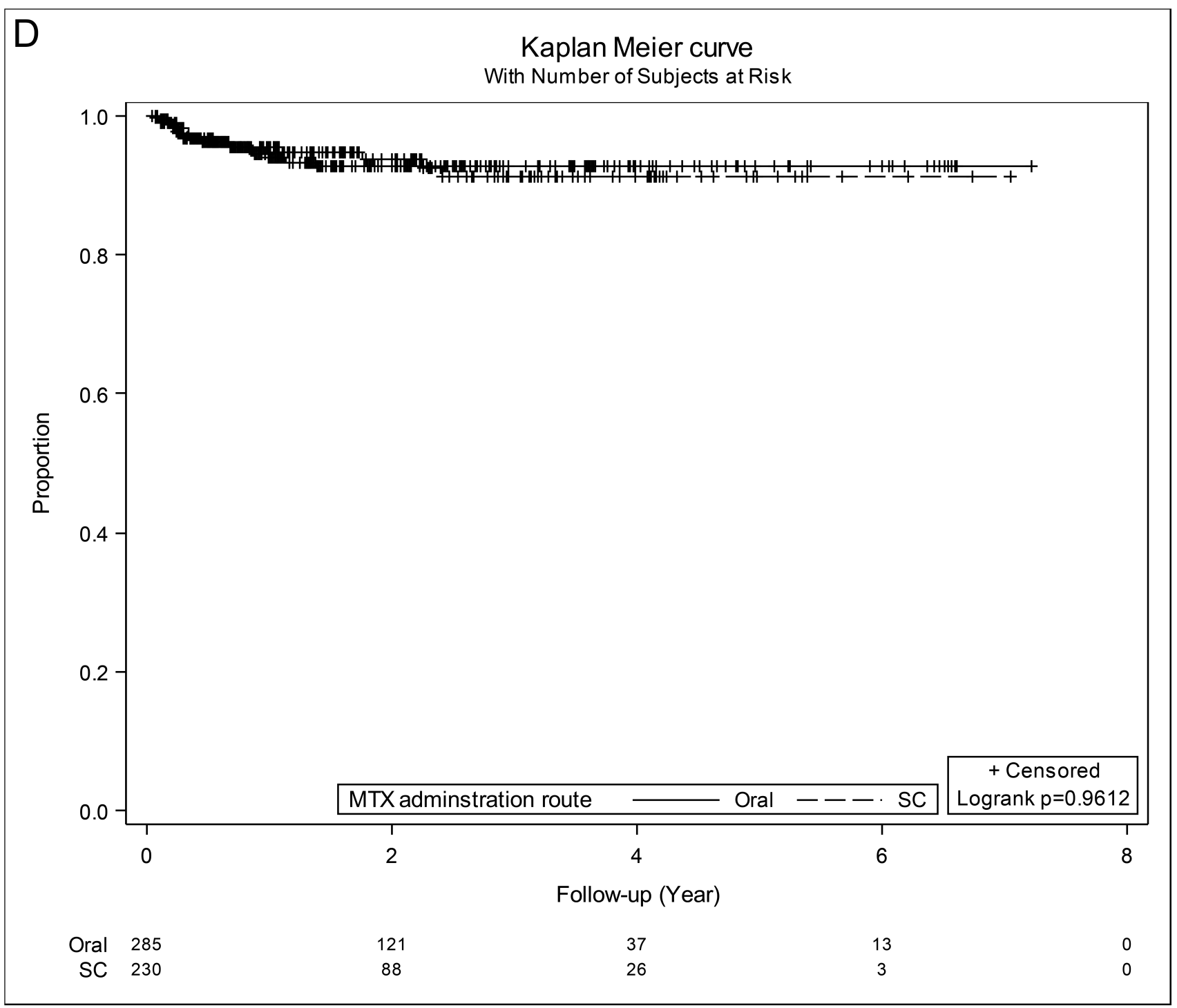

Figure 3. Continued

\section{APPENDIX 1.}

List of study collaborators. OBRI Investigators: Janet Pope, London, ON; Alfred Cividino, Hamilton, ON; Jane Purvis, Peterborough, ON; Vandana Ahluwalia, Brampton, ON; Sangeeta Bajaj, Brampton, ON; Arthur Karasik, Toronto, ON; Andrew Chow, Mississauga, ON; Brian Hanna, Kitchener, ON; Catherine Alderdice, Guelph, ON; Nader Khalidi, Hamilton, ON; Ali Shickh, Bowmanville, ON; Frances Leung, Sault Ste. Marie, ON; Bindee Kuriya, Toronto, ON; Edward Keystone, Toronto, ON; Jackie Hochman, Toronto, ON; Pooneh Akhavan, Toronto, ON; Elaine Soucy, Mississauga, ON; Felix Leung, Scarborough, ON; Ami Mody, Mississauga, ON; Angela Montgomery, Mississauga, ON; Michael Aubrey, Newmarket, ON; Edward $\mathrm{Ng}$, Newmarket, ON; Heather McDonald Blumer, Toronto, ON; Zareen Ahmad, Toronto, ON; Mark Matsos, Hamilton, ON; Raj Carmona, Hamilton, ON; Shikha Mittoo, Toronto, ON; Allan Kagal, Maple, ON; Sankalp Bhavsar, Burlington, ON; Arthur Bookman, Toronto, ON; Lori Albert, Toronto, ON; Saeed Shaikh, St. Catharines, ON; Jonathan Stein, Toronto, ON; Nicole LeRiche, London, ON; Andy Thompson, London, ON; Gina Rohekar, London, ON; Sherry Rohekar, London, ON; Raman Rai,
Hamilton, ON; Viktoria Pavlova, Ancaster, ON; Vandana Ahluwalia, Orangeville, ON; Sangeeta Bajaj, Orangeville, ON; Sanjay Dixit, Burlington, ON; Manisha Mulgund, Hamilton, ON; Dana Cohen, Maple, ON; Patricia Ciaschini, Sault Ste. Marie, ON; Simon Carette, Toronto, ON; Sindhu Johnson, Toronto, ON; Nigil Haroon, Toronto, ON; Nooshin Samadi, Newmarket, ON; Louise Perlin, Toronto, ON; Rachel Shupak, Toronto, ON; Dharini Mahendira, Toronto, ON; Thanu Ruban, Markham, ON; Raja Bobba, Hamilton, ON; Douglas Smith, Ottawa, ON; Jacob Karsh, Ottawa, ON; Anna Jaroszynska, Oakville, ON; Derek Haaland, Barrie, ON; Margaret Larche, Hamilton, ON; Vandana Ahluwalia, Brampton, ON; Sangeeta Bajaj, Brampton, ON; Raman Joshi, Brampton, ON; Tripti Papneja, Brampton, ON; Antonio Cabral, Ottawa, ON; Sibel Aydin, Ottawa, ON; Ines Midzic, Ottawa, ON; Nataliya Milman, Ottawa, ON; Rafat Faraawi, Kitchener, ON; Julie Brophy, Guelph, ON; Mary Bell, Toronto, ON; Grey Choy, Toronto, ON; Sharron Sandhu, Toronto, ON; Emily McKeown, Toronto, ON; Shirley Chow, Toronto, ON. 